\title{
Inhibition of nuclear factor- $\kappa$ B by 6-O-acetyl shanzhiside methyl ester protects brain against injury in a rat model of ischemia and reperfusion
}

\author{
Wanglin Jiang ${ }^{1,2}$, Shuping Zhang ${ }^{1 *}$, Fenghua Fu ${ }^{3^{*}}$, Haibo $\mathrm{Zhu}^{2}$, Jian $\mathrm{Hou}^{2}$
}

\begin{abstract}
Background: Recent studies have demonstrated an inflammatory response associated with the pathophysiology of cerebral ischemia. The beneficial effects of anti-inflammatory drugs in cerebral ischemia have been documented. When screening natural compounds for drug candidates in this category, we isolated 6-O-acetyl shanzhiside methyl ester (ND02), an iridoid glucoside compound, from the leaves of Lamiophlomis rotata (Benth.) Kudo. The objectives of this study were to determine the effects of ND02 on a cultured neuronal cell line, SH-SY5Y, in vitro, and on experimental ischemic stroke in vivo.

Methods: For TNF- $\alpha$-stimulated SH-SY5Y cell line experiments in vitro, SH-SY5Y cells were pre-incubated with ND02 $(20 \mu \mathrm{M}$ or $40 \mu \mathrm{M})$ for $30 \mathrm{~min}$ and then incubated with TNF- $\alpha(20 \mathrm{ng} / \mathrm{ml})$ for $15 \mathrm{~min}$. For in vivo experiments, rats were subjected to middle cerebral artery occlusion (MCAO) for $1 \mathrm{~h}$ followed by reperfusion for $23 \mathrm{~h}$.

Results: ND02 treatment of SH-SY5Y cell lines blocked TNF- $\alpha$-induced nuclear factor- $\kappa \mathrm{B}$ (NF- $\kappa \mathrm{B}$ ) and I $\kappa \mathrm{B}-\alpha$ phosphorylation and increased Akt phosphorylation. LY294002 blocked TNF- $\alpha$-induced phosphorylation of Akt and reduced the phosphorylation of both $\mid \kappa \mathrm{B}-\alpha$ and NF- $\kappa \mathrm{B}$. At doses higher than $10 \mathrm{mg} / \mathrm{kg}$, ND02 had a significant neuroprotective effect in rats with cerebral ischemia and reperfusion (I/R). ND02 (25 mg/kg) demonstrated significant neuroprotective activity even after delayed administration $1 \mathrm{~h}, 3 \mathrm{~h}$ and $5 \mathrm{~h}$ after $\mathrm{I} / \mathrm{R}$. ND02, $25 \mathrm{mg} / \mathrm{kg}$, attenuated histopathological damage, decreased cerebral Evans blue extravasation, inhibited NF- $\kappa$ B activation, and enhanced Akt phosphorylation.
\end{abstract}

Conclusion: These data show that ND02 protects brain against I/R injury with a favorable therapeutic time-window by alleviating cerebral I/R injury and attenuating blood-brain barrier (BBB) breakdown, and that these protective effects may be due to blocking of neuronal inflammatory cascades through an Akt-dependent NF- $\kappa$ B signaling pathway.

\section{Background}

Ischemic brain injury resulting from diseases such as stroke is the third leading cause of death in the United States and a leading cause of lethality and disability in European countries. Although much is now known about the molecular consequences of ischemic brain injury, few therapeutic treatments have proven successful in clinical trials [1]. The inflammatory response to brain injury plays a vital role in the pathogenesis of

\footnotetext{
* Correspondence: davidjiangwl@163.com; fenghua@luye.cn

'Institute of Material Medica, Binzhou Medical University, Yantai, 264003, PR China

${ }^{3}$ School of Pharmacy, Yantai University, Yantai 264003, PR China Full list of author information is available at the end of the article
}

stroke [2,3]. Previous studies have demonstrated that agents with anti-inflammatory action have therapeutic potential for experimental stroke [4].

There is ample evidence indicating that NF- $\kappa \mathrm{B}$ is activated in cerebral ischemia and reperfusion (I/R), especially in neurons [5-8]. This suggests that inhibition of NF- $\kappa \mathrm{B}$ may represent a treatment strategy in ischemic stroke. Previous studies have shown that aspirin and several structurally diverse compounds provide neuroprotection during cerebral ischemia via inhibition of NF- $\kappa$ B activation [9-13].

Akt, a serine/threonine protein kinase, plays a critical role in controlling the balance between apoptosis and cell survival in response to extra- and intracellular

\section{C) Biomed Central}


signaling. Pathological mechanisms after cerebral ischemia involve phosphoinositide 3-kinase (PI3K)/Akt [14-17]. Akt signaling exerts its neuroprotective role in cerebral ischemia animal models [18-20] via blocking of $\mathrm{NF}-\kappa \mathrm{B}$ activation, through IkB phosphorylation and degradation [21].

6-O-acetyl shanzhiside methyl ester (ND02, Figure 1) is an iridoid glucoside compound isolated from the leaves of Lamiophlomis rotata (Benth.) Kudo., which is a Chinese folk medicinal plant in Xi-zang (Tibet). For thousands of years, Lamiophlomis rotata has been used in pain alleviation, detumescence, hemostasis, marrow reinforcement and promotion of blood circulation to remove stasis [22]. There are many iridoid glucoside compounds in the leaves of Lamiophlomis rotata (Benth.) Kudo, however, ND02 and 8-O-acetyl shanzhiside methyl ester are the main components. Previous studies have shown that 8 -O-acetyl shanzhiside methyl ester attenuates apoptosis and ameliorates mitochondrial energy metabolism in rat cortical neurons exposed to oxygen-glucose deprivation [23]. ND02 is also found in the root of Phlomis medicinalis Die [24]. The objective of this study was to determine the effects of ND02 on the inflammatory response of neurons and to explore whether ND02 can protect brain against injury in a rat model of $\mathrm{I} / \mathrm{R}$.

\section{Methods}

\section{Materials}

ND02 (Molecular Formula: $\mathrm{C}_{19} \mathrm{H}_{28} \mathrm{O}_{12}$; CAS NO.: 110186-13-5; Chemical name: methyl(1 S,4aS,5R,7 S,7aS)-5-acetyloxy-7-hydroxy-7-methyl-1-[(2 S,3R,4 S,5

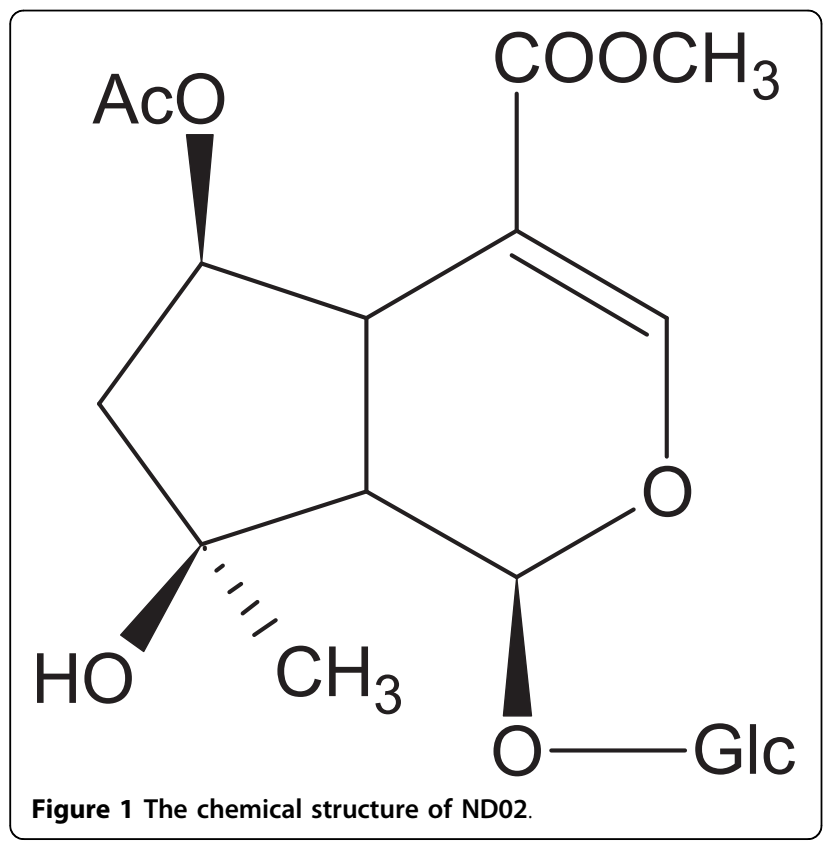

S,6R)-3,4,5-trihydroxy-6-(hydroxymethyl)oxan-2-yl] oxy4a,5,6,7a-tetrahydro-1H-cyclopenta [c] pyran-4-carboxylate, purity $>98.5 \%$ ) was provided by the State Key Laboratory of Long-acting Extended-Release and Targeting Drug Delivery Systems (Luye Pharma Group Ltd.), Yantai, P. R. China). Its extraction and isolation were carried out according to a previously described procedure [24].

\section{Cell culture}

Human neuroblastoma (SH-SY5Y) cells were obtained from the Shanghai cell bank of the Chinese Academy of Sciences. SH-SY5Y cells were cultured and maintained in $\mathrm{F} 12+\operatorname{DMEM}(1,1, \mathrm{v} / \mathrm{v})$ media, supplemented with $10 \% \mathrm{FBS}$ and $1 \%$ penicillin/streptomycin. Cells were kept at $37^{\circ} \mathrm{C}$ in a humidified $5 \% \mathrm{CO}_{2} / 95 \%$ air incubator. For TNF- $\alpha$-stimulated SH-SY5Y cell line experiments in vitro, SH-SY5Y cells $\left(5 \times 10^{6}\right)$ were pre-incubated with PI3 kinase inhibitor, LY294002 (30 $\mu \mathrm{M}$, Calbiochem, La Jolla, CA) or ND02 $(20 \mu \mathrm{M}$ or $40 \mu \mathrm{M})$ for $30 \mathrm{~min}$ and then incubated with TNF- $\alpha$ (20 ng/ml) for $15 \mathrm{~min}$.

\section{Western blot analysis}

Cells were cultured for $24 \mathrm{~h}$, then washed twice with ice cold PBS on ice and lysed in NP40 lysis buffer (Biosource, Camarillo, CA, USA) (50 mM Tris, pH 7.4, 250 $\mathrm{mM} \mathrm{NaCl}, 5 \mathrm{mM}$ EDTA, $50 \mathrm{mM} \mathrm{NaF}, 1 \mathrm{mM} \mathrm{Na} \mathrm{VO}_{4}$, $1 \% \mathrm{NP}-40$ and $0.02 \% \mathrm{NaN}_{3}$ ) supplemented with $1 \mathrm{mM}$ PMSF and $1 \times$ protease inhibitor cocktail (Sigma, Saint Louis, MO, USA). Equal amounts of cell protein $(50 \mu \mathrm{g})$ were separated by SDS-PAGE and analyzed by western blot using specific antibodies to phospho-I $\kappa \mathrm{B}-\alpha$, phospho-NF- $\kappa \mathrm{B}$, phospho-Akt and $\beta$-actin (as a loading control). The antibodies were all purchased from Beijing Biosynthesis Biotechnology Company (Beijing, P. R. China). Optical densities of the bands were scanned and quantified with a Gel Doc 2000 (Bio-Rad Laboratories (UK) Ltd). Data were normalized against those of the corresponding $\beta$-actin bands. Results were expressed as fold increase over control.

\section{Animals}

Adult male Sprague-Dawley rats were obtained from Shandong Luye-Pharmaceutical Company (Yantai, P. R. China). All animals were housed individually at $22 \pm$ $2{ }^{\circ} \mathrm{C}$ and a relative humidity of $50 \pm 10 \%$ and with a 12-h light/dark cycle, and had free access to chow and water. The experimental procedures were approved by the Binzhou Medical University's Administrative Panel on Laboratory Animal Care.

\section{Rat cerebral ischemia study protocol}

The body weight of the rats at the time of the experiments was 280-310 g. After 1 week of acclimatization, 
rats were anesthetized with chloral hydrate $(350 \mathrm{mg} / \mathrm{kg}$, i.p.). Rectal temperatures were recorded and maintained at $37^{\circ} \mathrm{C}$ during surgery with a heating-pad. The middle cerebral artery occlusion (MCAO) operation was carried out according to a previous procedure with minor modifications [25]. The left common carotid artery was occluded, and the branches of the external carotid artery were dissected and divided. The internal carotid artery was followed rostrally and a 4-0 filament (Beijing Shadong Biology Company, P. R. China; the diameter of the filament is 0.25 , but the diameter of the tip is $0.34 \mathrm{~mm}$ to create a globular stopper) was introduced into the internal carotid artery and advanced until resistance was felt. The filament was removed after $1 \mathrm{~h}$. The rats were kept under $24^{\circ} \mathrm{C}-25^{\circ} \mathrm{C}$ conditions for the first $24 \mathrm{~h}$ after surgery.

For dose-response studies, 105 rats were randomly divided into 7 groups of 15 rats each. ND02 at doses of $1.6,4,10,25$ and $62.5 \mathrm{mg} / \mathrm{kg}$ was administered as a bolus injection into the tail vein $30 \mathrm{~min}$ after reperfusion. (The ND02 was dissolved in sterile saline to make stock solutions, and dilutions were then prepared for different final concentrations.) Sham or vehicle-treated rats were injected with saline. Rectal temperature was determined once every $3 \mathrm{~h}$ for a total of 8 times. Neurological deficits were determined $24 \mathrm{~h}$ after ischemia, followed by brain infarct volume examinations.

For therapeutic time-window studies, 90 rats were randomly divided into 6 groups. ND02 at a dose of 25 $\mathrm{mg} / \mathrm{kg}$ was administered as a bolus injection into the tail vein at $1 \mathrm{~h}, 3 \mathrm{~h}, 5 \mathrm{~h}$ and $7 \mathrm{~h}$ after reperfusion. Vehicle-treated rats were injected with saline. Neurological deficits were determined $24 \mathrm{~h}$ after ischemia, followed by brain infarct examinations.

For anti-inflammatory mechanism studies, 90 rats were randomly divided into three groups, and each of these into three subgroups of 10 rats each. ND02 at a dose of $25 \mathrm{mg} / \mathrm{kg}$ was administered as a bolus injection into the tail vein $30 \mathrm{~min}$ after reperfusion. Sham or vehicle-treated rats were injected with saline. The three groups were evaluated for Evans blue extravasation, by western blots, and for histopathological damage by NeuN staining $24 \mathrm{~h}$ after ischemia.

For long-term studies, 40 rats were randomly divided into two groups of 20 rats each: an ND02-treated $(25 \mathrm{mg} / \mathrm{kg}$ ) group and a vehicle-treated group. ND02 was administered as a bolus injection into the tail vein $30 \mathrm{~min}$ after reperfusion and once every $24 \mathrm{~h}$ for 7 consecutive days. Vehicle-treated rats were injected with saline. Neurological deficits were determined on the 3rd, 7 th and 14th days after I/R. Fourteen days after I/R, 8 rats in each group were randomly selected for brain infarct examination.

\section{Evaluation of neurological deficits}

Neurological deficits were evaluated using a modified six-point scoring method [26] by an investigator who was blinded to the experimental treatment groups. The scale is 0 : no neurological deficit (normal); 1 : failure to extend the left forepaw fully (mild); 2 : circling to the left (moderate); 3: falling to the left (severe); 4: no spontaneous walking with a depressed level of consciousness (very severe) and 5: dead.

\section{Evaluation of infarct volume and brain water content}

Rats were decapitated $23 \mathrm{~h}$ after reperfusion, and their brains quickly removed. Total wet weight of the brain was measured accurately, and each brain was then sliced into five coronal sections of 2-mm thickness each and stained with a $2 \%$ solution of tetrazolium chloride (TTC, Sigma) in saline at $37^{\circ} \mathrm{C}$ for $20 \mathrm{~min}$, and then photographed. The images were digitized and used to calculate infarct volume with a Compix system computer (C imaging 1280 system),. Afterwards, brain water content was determined as an indicator of cerebral edema using a wet/dry method as previously described [27].

\section{Evaluation of blood-brain barrier (BBB) leakage with Evans blue extravasation}

Determination of Evans blue extravasation was based on a previous method [28] with minor modifications. After reperfusion, $0.1 \mathrm{ml}$ of $4 \%$ Evans blue (Urchem, Shanghai, P. R. China) in $0.9 \%$ saline was intravenously administered. Twenty-three hours after $I / R$, each rat was perfused with $20 \mathrm{ml} 10 \mathrm{U} / \mathrm{ml}$ heparinized saline to wash out blood. The brain was then isolated, weighed and homogenized in $50 \%$ solution of trichloroacetic acid. After centrifugation at $400 \times \mathrm{g}$ for $20 \mathrm{~min}$, the supernatant was spectrophotometrically measured at $610 \mathrm{~nm}$. Cerebral Evans blue was quantified as micrograms of dye per gram of wet weight.

\section{Western blots analysis in $\mathrm{I} / \mathrm{R}$ rats}

For western blot analysis of collected brain tissues, the tissues were defrosted and immersed in ice-cold lysis buffer (50 mM Tris- $\mathrm{HCl}, 1 \mathrm{mM}$ EDTA, $1 \mathrm{mM}$ EGTA, $0.5 \mathrm{mM} \mathrm{Na}_{3} \mathrm{VO}_{4}, 0.1 \%$ 2-mercaptoethanol, 1\% Triton $\mathrm{X}-100,50 \mathrm{mM} \mathrm{NaF}, 5 \mathrm{mM}$ sodium pyrophosphate, $10 \mathrm{mM}$ sodium $\beta$-glyceropyrophosphate, $0.1 \mathrm{mM}$ phenylmethanesulfonyl fluoride, and protease inhibitor mixture) for $10 \mathrm{~min}$. Supernatant was collected after a shake in $1 \% p$-nitorphenyl phosphate for $10 \mathrm{~s}$, and centrifugation at $4^{\circ} \mathrm{C}$ and $12,000 \times g$ for $30 \mathrm{~s}$. Equal amounts of protein were separated by SDS-PAGE and analyzed by western blot using antibodies (Beijing Biosynthesis Biotechnology Company, P. R. China) to phospho-I $\kappa \mathrm{B}-\alpha$, phospho-NF- $\kappa \mathrm{B}$, phospho-Akt and 
$\beta$-actin. Optical densities of the resultant bands were scanned and quantified with a Gel Doc 2000 (Bio-Rad). The data were normalized against those of the corresponding $\beta$-actin bands. Results were expressed as fold increase over sham animals.

\section{NeuN staining}

NeuN-immunolabeling was carried out by incubating free floating coronal sections $(5 \mu \mathrm{m})$ with anti-NeuN antiserum and 3,3-diaminobenzidine tetra hydrochloride (DAB). First, coronal sections were washed twice for 20 min in TBS buffer $(0.15 \mathrm{M} \mathrm{NaCl} ; 0.1 \mathrm{M}$ Tris- $\mathrm{HCl}, \mathrm{pH}$ 7.5) at room temperature. This was followed by a 30 min incubation in TBS-BSA [TBS containing $1 \%(\mathrm{w} / \mathrm{v})$ BSA and $3 \%$ normal goat serum (NGS)] at room temperature to block nonspecific antibody binding. The sections were then incubated overnight with 1:500 antiNeuN antiserum (Beijing Biosynthesis Biotechnology Company, P.R. China) diluted in $1 \%$ NGS in TBS at $4{ }^{\circ} \mathrm{C}$. After three 10-min washings with $1 \%$ NGS in TBS, the sections were incubated with 1:250 biotinylated antimouse IgG (Secondary antibody, Fuzhong Maixin Biotechnology Company, P.R. China) for $1 \mathrm{~h}$ in $1 \%$ NGS in TBS at room temperature. NeuN-immunostaining was visualized using the streptomycete antibiotin-peroxidase solution and DAB.

To evaluate neurological damage after cerebral I/R 24 h, the left hemisphere of each brain was cut coronally into three blocks from the level of the optic chiasm and the infundibular stem of the hypophysisi. The middle block was further cut into three sub-blocks. The middle subblock $(0.1 \times 0.1 \mathrm{~cm})$ was embedded in paraffin and immunoreacted for NeuN. NeuN-immunopositive cells were counted at $400 \times$ magnification in three selected fields in the central zone of the middle sub-block $(0.1 \times 0.1 \mathrm{~cm})$. A final value for number of NeuN-immunopositive cells was calculated by averaging the counts of three fields.

To evaluate brain infarct volume after cerebral I/R of 14 days duration, rats were killed 14 days after I/R. The brains were fixed by transcardial perfusion with saline, followed by perfusion and immersion in $4 \%$ paraformaldehyde before being embedded in paraffin. Seven coronal sections of tissue were processed and immunoreacted for NeuN for calculation of volume of cerebral infarction [29]. Indirect infarct area was calculated by subtracting the intact area of the ipsilateral hemisphere from the area of the contralateral hemisphere [29]. Infarct volume is presented as a volume percentage of the lesion compared with the contralateral hemisphere.

\section{Statistical analysis}

Neurological deficit scores between groups were analyzed using a nonparametric test. Quantitative data from the experiments are expressed as mean \pm SD. Statistical significance was determined by one-way analysis of variance (ANOVA) followed by Dunnett's test. In all cases, differences were considered significant if $P<0.05$.

\section{Results \\ ND02 blocks NF- $\kappa$ B activation through Akt signaling pathway}

We compared the effect of ND02 on TNF- $\alpha$-induced $(20 \mathrm{ng} / \mathrm{ml}$ for $15 \mathrm{~min}$ ) activation of $\mathrm{I} \kappa \mathrm{B}-\alpha, \mathrm{NF}-\kappa \mathrm{B}$ and Akt in the SH-SY5Y cell line to that of a selective PI3K inhibitor, LY294002. The results (Figure 2) show that pretreatment of SH-SY5Y cells with LY294002 (30 $\mu \mathrm{M})$ for 30 min blocked TNF- $\alpha$-induced phosphorylation of Akt and reduced the phosphorylation of both $\mathrm{I} \kappa \mathrm{B}-\alpha$ and NF- $\kappa$ B. ND02, $20 \mu \mathrm{M}$ and $40 \mu \mathrm{M}$ treatments of SHSY5Y cells, blocked TNF- $\alpha$-induced $\mathrm{I} \kappa \mathrm{B}-\alpha$ and NF- $\kappa \mathrm{B}$ phosphorylation, while increasing Akt phosphorylation (Figure 2).

\section{ND02 reduces brain infarct volume, brain water content and neurological deficit scores in cerebral I/R rats}

Cerebral I/R leads to severe behavioral disturbance and histological changes in rats. Compared with sham-operated animals, neurological deficit, cerebral infarct volume and cerebral edema were significant higher in cerebral I/R rats.

The results of dose-response studies are shown in Table 1. ND02 at doses of 10, 25 and $62.5 \mathrm{mg} / \mathrm{kg}$, administered intravenously $30 \mathrm{~min}$ after $\mathrm{I} / \mathrm{R}$, decreased neurological deficit scores, reduced cerebral infarct volume and brain water content in a dose dependent manner.

The results of therapeutic time-window studies are shown in Table 2 . ND02 at a dose of $25 \mathrm{mg} / \mathrm{kg}$ significantly decreased neurological deficit scores, reduced cerebral infarct volume and brain water content even with delayed administration $1 \mathrm{~h}, 3 \mathrm{~h}$ and $5 \mathrm{~h}$ after I/R. Obviously, earlier administration of this compound brings more therapeutic benefit.

The results of long-term studies are shown in Table 3. ND02 at an i.v. dose of $25 \mathrm{mg} / \mathrm{kg} 30 \mathrm{~min}$ after I/R significantly decreased neurological deficit scores and reduced cerebral infarction 14 days after $I / R$. The results of NeuN immunolabeling indicated that this is likely due to a significantly increased number of surviving neurons $24 \mathrm{~h}$ and 14 days after cerebral I/R, as shown in Figure 3A and Figure 3B. Thus, it is clear that early treatment with ND02 provides long-term benefits for neuronal functional recovery after cerebral $I / R$.

\section{ND02 attenuates the increase of cerebral Evans blue extravasation in $\mathrm{I} / \mathrm{R}$ rats}

Evans blue extravasation was used to assess of $\mathrm{BBB}$ breakdown after cerebral ischemia. The results of Evans blue extravasation clearly shows that this pathological 


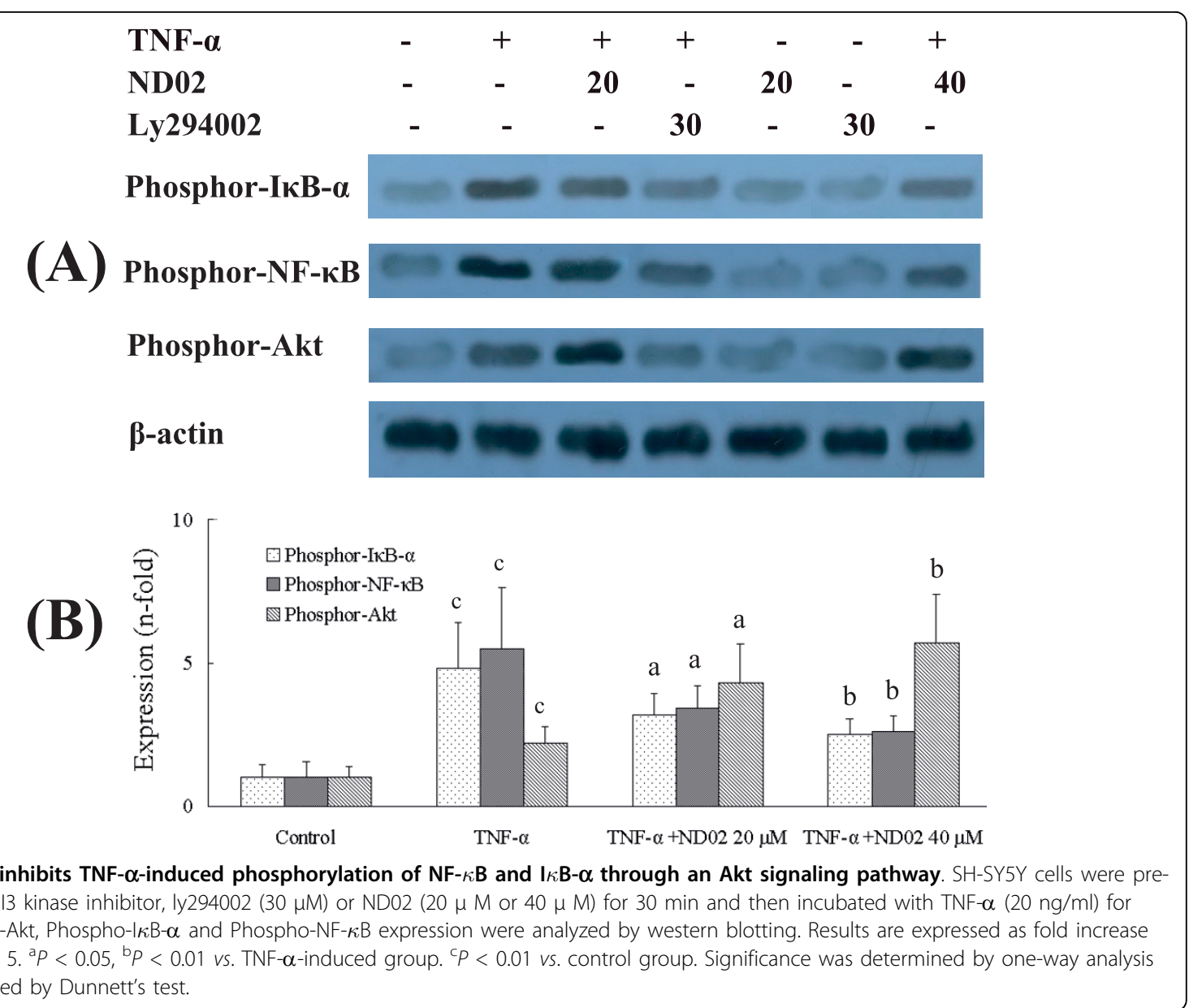

consequence of cerebral $\mathrm{I} / \mathrm{R}$ is significantly attenuated by ND02 treatment, as shown in Table 4.

\section{ND02 attenuates the decrease of NeuN-immunopositive neurons}

The number of NeuN-immunopositive neuron is a reliable indicator of cerebral injury. After $24 \mathrm{~h}$ of IR, the number of NeuN-immunopositive neuron was decreased in cerebral cortex, as shown in Figure 3B. ND02 treatment $(25 \mathrm{mg} / \mathrm{kg})$ alleviated this damage to neurons $24 \mathrm{~h}$ and 14 days after cerebral I/R.

\section{ND02 attenuates cerebral NF- $\kappa$ B activation in cerebral I/R rats}

To investigate the molecular mechanism of the ND02 protective effects, NF- $\kappa \mathrm{B}$ activation and phosphorylated Akt were examined. Phosphorylation of $\mathrm{I} \kappa \mathrm{B}-\alpha$ and NF- $\kappa \mathrm{B}$ occurred in rats after cerebral $I / R$, but were not

Table 1 Effects of ND02 on survival, neurological scores, infarct volume, and brain water content in ischemiareperfused rats: a dose-response study

\begin{tabular}{|c|c|c|c|c|}
\hline Group & Survival (\# rats) & Neurological scores (median/range) & Infarct volume (\%) & Brain water content (\%) \\
\hline Sham & $15 / 15$ & - & - & $76.8 \pm 0.5$ \\
\hline Vehicle-treated & $9 / 15$ & $4 / 2$ & $27.4 \pm 6.3$ & $78.8 \pm 0.4$ \\
\hline ND02 $1.6 \mathrm{mg} / \mathrm{kg}$ & $9 / 15$ & $4 / 3$ & $24.8 \pm 4.2$ & $78.6 \pm 0.4$ \\
\hline ND02 4 mg/kg & $10 / 15$ & $4 / 3$ & $23.3 \pm 4.8$ & $78.4 \pm 0.5$ \\
\hline ND02 $10 \mathrm{mg} / \mathrm{kg}$ & $10 / 15$ & $3 / 3^{*}$ & $19.7 \pm 6.2^{*}$ & $78.2 \pm 0.7^{*}$ \\
\hline ND02 25 mg/kg & $11 / 15$ & $3 / 4^{* *}$ & $17.4 \pm 4.8^{* *}$ & $77.9 \pm 0.5^{* *}$ \\
\hline ND02 62.5 mg/kg & $12 / 15$ & $2 / 4^{* *}$ & $12.8 \pm 3.5^{* *}$ & $77.8 \pm 0.5^{* *}$ \\
\hline
\end{tabular}

Data are means $\pm S D$, with $\mathrm{n}=15$ for each group. ND02, at doses ranging from 1.6 to $62.5 \mathrm{mg} / \mathrm{kg}$, was administered intravenously 30 min after cerebral $\mathrm{l} / \mathrm{R}$. ${ }^{\#} P<0.01$ vs. sham group; ${ }^{*} P<0.05$, ${ }^{*} P<0.01$ vs vehicle-treated group. Cerebral infarct volume and brain water content between groups were compared using one-way ANOVA followed by Dunnett's test. Neurological scores between groups were compared using a nonparametric test. 
Table 2 Effects of ND02 on survival, neurological scores, infarct volume, and brain water content in ischemiareperfused rats: a therapeutic time-window study

\begin{tabular}{lccccc}
\hline Group & & Survival (\# rats) & Neurological scores (median/range) & Infacrt volume (\%) & Brain water content (\%) \\
\hline Sham & & $15 / 15$ & - & - & $76.7 \pm 0.5$ \\
Vehicle-treated & $10 / 15$ & $4 / 2$ & $26.1 \pm 4.5$ & $78.9 \pm 0.4$ \\
& $1 \mathrm{~h}$ & $13 / 15$ & $2 / 3^{* *}$ & $15.8 \pm 3.9^{* *}$ & $77.9 \pm 0.6^{* *}$ \\
ND02 25 & $3 \mathrm{~h}$ & $12 / 15$ & $3 / 4^{*}$ & $18.6 \pm 5.1^{* *}$ & $78.1 \pm 0.4^{* *}$ \\
& $5 \mathrm{~h}$ & $11 / 15$ & $3 / 3^{*}$ & $21.8 \pm 4.1^{*}$ & $78.4 \pm 0.5^{*}$ \\
& $7 \mathrm{~h}$ & $10 / 15$ & $3 / 3$ & $22.9 \pm 6.6$ & $78.6 \pm 0.4$ \\
\hline
\end{tabular}

Data are means \pm SD, with $\mathrm{n}=15$ for each group. ND02 was administered at a dose of $25 \mathrm{mg} / \mathrm{kg}$ at $1 \mathrm{~h}, 3 \mathrm{~h}, 5 \mathrm{~h}$ and $7 \mathrm{~h}$ after cerebral l/R. Data are means \pm SD. ${ }^{*} P<0.01$ vs. sham group; ${ }^{*} P<0.05,{ }^{*} P<0.01$ vs vehicle-treated group. Cerebral infarct volumes of different groups were compared using one-way ANOVA followed by Dunnett's test. Neurological deficit scores between groups were compared using a nonparametric test.

present in the sham group, as shown in Figure 4. ND02 treatment reduced phosphorylated $\mathrm{I} \kappa \mathrm{B}-\alpha$ and $\mathrm{NF}-\kappa \mathrm{B}$ levels, while increasing phosphorylated Akt levels. These data indicate that ND02 inhibits NF- $\kappa \mathrm{B}$ activation through Akt signaling pathway in cerebral I/R rats.

\section{Discussion}

In the present study, we observed significant improvement of brain injury after treatment with ND02 in rats subjected to cerebral I/R challenge in an I/R model. Stoke triggers an inflammatory reaction that progresses for hours after the onset of a stroke, and this inflammation plays a central role in the pathogenesis of neuronal injury in ischemic stroke. Inflammation is thought to contribute to the genesis of secondary damage as the consequence of activation of resident perivascular and parenchymal macrophages, and infiltration of peripheral inflammatory cells [30]. This postischemic inflammation occurs a few hours to days after a primary ischemic event, and is associated with delayed injury [31]. In particular, inflammatory reactions contribute to the late stages of ischemic injury and to worsened neurological outcome through multiple mechanisms [32]. The present study indicates that ND02 has anti-inflammatory effects (Table 4, Figure 2 and Figure 4). Treatment with ND02 especially provided long-term benefits for neuronal functional recovery after cerebral I/R (Table 3). This suggests that the neuroprotective effects of ND01 may be to block the inflammatory response. In addition, determinations of ND02 in brain tissue by HPLC after $i . v$. administration of ND02 $25 \mathrm{mg} / \mathrm{kg}$ indicate that ND02 can penetrate the blood-brain barrier.

Infarction, the main pathophysiological outcome of cerebral ischemia, entails neuronal degeneration and necrosis [33]. Our results (Table 1) reveal that ND02 treatment produces significant reduction in cerebral infarct volume in cerebral I/R model rats. Neuronal degeneration and necrosis have been found to be correlated to deficits in behavioral disturbance, and the present study shows that neurological scores are improved by treatment with ND02 (Table 1). NeuN is a resoluble nuclear protein with a molecular weight of $46 \mathrm{kDa}$, and is a widely used marker for mature neurons. NeuN is expressed in the nucleus and cell bodies of most neurons but not in glial cells, including oligodendrocytes, astrocytes, and microglial cells [34,35]. Immunoreactivity for NeuN has been reported to decrease dramatically following CNS injury [36-39], and $\mathrm{NeuN}$ is a sensitive marker for injured neurons early after ischemic challenge [40]. Thus the number of NeuN-immunopositive neuron in ischemic cerebral cortex is a reliable indicator of cerebral injury. Our data (Figure 3) demonstrate that i.v. ND02, $25 \mathrm{mg} / \mathrm{kg}$, attenuates the decrease in NeuNimmunopositive neurons in ischemic cerebral cortex

Table 3 Effects of ND02 on survival, neurological scores, infarct volume, and brain water content in ischemiareperfused rats: a long-term study

\begin{tabular}{|c|c|c|c|c|}
\hline Group & Time (days) & Survival (\# rats) & Neurological scores (median/range) & Infarct volume (\%) \\
\hline & 3 & $15 / 20$ & $4 / 3$ & \\
\hline \multirow[t]{3}{*}{ Vehicle-treated } & 7 & $14 / 20$ & $3 / 4$ & \\
\hline & 14 & $13 / 20$ & $3 / 4$ & $27.6 \pm 5.8$ \\
\hline & 3 & $17 / 20$ & $2 / 4^{* *}$ & \\
\hline \multirow[t]{2}{*}{ ND02 25} & 7 & $16 / 20$ & $2 / 4^{*}$ & \\
\hline & 14 & $16 / 20$ & $2 / 4^{*}$ & $13.9 \pm 4.7^{* *}$ \\
\hline
\end{tabular}

ND02 was administered at a dose of $25 \mathrm{mg} / \mathrm{kg}$ as a single intravenous bolus injection $30 \mathrm{~min}$ after cerebral l/R. This led to significantly decreased neurological deficit scores and reduced cerebral infarct volume within 14 days after I/R. Data are means \pm SD, each group is 20 rats. ${ }^{*} P<0.05,{ }^{* *} P<0.01$ vs vehicle-treated group. Cerebral infarct volumes of different groups were compared using one-way ANOVA followed by Dunnett's test. Neurological deficit scores between groups were compared using a nonparametric test. 

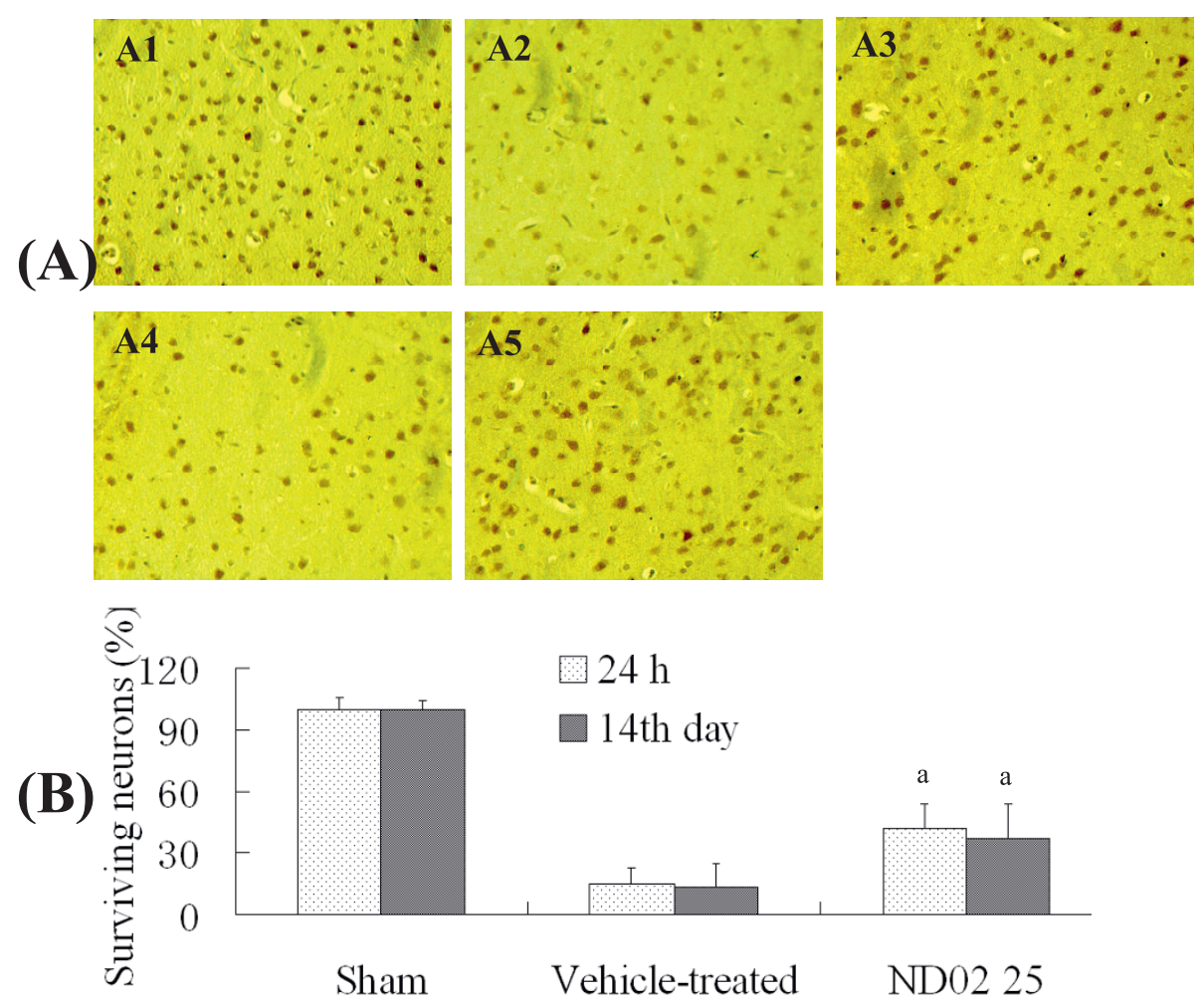

Figure 3 Effect of ND02 on neurological damage $\mathbf{2 4}$ h and $\mathbf{1 4}$ days after cerebral ischemia-reperfusion (I/R). Figure. 3A: Effect of ND02 on cerebral pathological damage after cerebral I/R. Sections were stained with NeuN after fixation. A1: Sham group; A2: Vehicle-treated group (24 h); A3: ND02 25 mg/kg group; A4: Vehicle-treated group (14th day); A5: ND02, 25 mg/kg, group (14th day). Figure 3B: Effect of ND02 on the NeuNimmunopositive neurons after cerebral I/R. Results were averaged and are expressed as number of NeuN-immunopositive neurons per section. Data are means $\pm S D, n=5 .{ }^{a} P<0.01$ vs vehicle-treated group. Significance was determined by one-way ANOVA followed by Dunnett's test.

$24 \mathrm{~h}$ and 14 days after I/R. This indicates that ND02 is potentially beneficial in treatment of cerebral ischemia.

BBB tight junction permeability is altered in ischemic stroke [41]. BBB breakdown occurs in the early phase (within $24 \mathrm{~h}$ ) of cerebral ischemia [42,43]. This breakdown of BBB leads to massive brain edema, which is the main cause of death in acute stroke [44]. The brain becomes devoid of protection from toxic substances carried by circulating blood upon BBB disruption. Attenuating $\mathrm{BBB}$ disruption provides a strong neuroprotective effect and ameliorates secondary injury [45]. Cerebral Evans blue extravasation is a commonly used biomarker of BBB permeability. Our data (Table 4) demonstrate that ND02, $25 \mathrm{mg} / \mathrm{kg}$ i.v., reduces cerebral Evans blue extravasation after cerebral I/R. These results indicate that ND02 improves cerebral I/R injury by attenuating BBB breakdown.

A recent update of the Stroke Therapy Academic Industry Roundtable Preclinical Recommendations [46] lists three potential reasons for failures in translating efficacious preclinical findings into successful clinical trial outcomes: (i) a very tight dose range with sa teep dose-response curve; (ii) inadequate investigation of therapeutic time-windows for initiation of treatment and (iii) differences in observation period between animal models and clinical trials. Consequently, we investigated the dose-response (Table 1), therapeutic time window (Table 2) and long-term efficacy (Table 3) of ND02 in cerebral I/R rats. Our data demonstrate that ND02 exerts potent and long-term neuroprotective effects with an appropriate dose-response curve and a favorable therapeutic time-window in the model of cerebral $I / R$.

It is well established that NF- $\kappa \mathrm{B}$ activation is associated with phosphorylation of $\mathrm{I} \kappa \mathrm{B}-\alpha$ and NF- $\kappa \mathrm{B}$ $[47,48]$. Animals exempted from NF- $\kappa$ B activation or

Table 4 Effect of ND02 on cerebral Evans blue extravasation in ischemia-reperfused rats

\begin{tabular}{ccc}
\hline Group & $\begin{array}{c}\text { Dose } \\
(\mathbf{m g} / \mathbf{k g})\end{array}$ & $\begin{array}{c}\text { Evans blue extravasation } \\
(\boldsymbol{\mu g} / \mathbf{g} \text { wet weight })\end{array}$ \\
\hline Sham & - & $0.47 \pm 0.11$ \\
Vehicle-treated & - & $3.31 \pm 0.62 \#$ \\
ND02 & 25 & $1.76 \pm 0.39^{* *}$ \\
\hline
\end{tabular}

Data are means $\pm S D$, with $n=10$ for each group. ${ }^{\#} P<0.01$ vs. sham group; ${ }^{*} P<0.05,{ }^{* *} P<0.01$ vs vehicle-treated animals. Significance was determined by one-way ANOVA followed by Dunnett's test. 


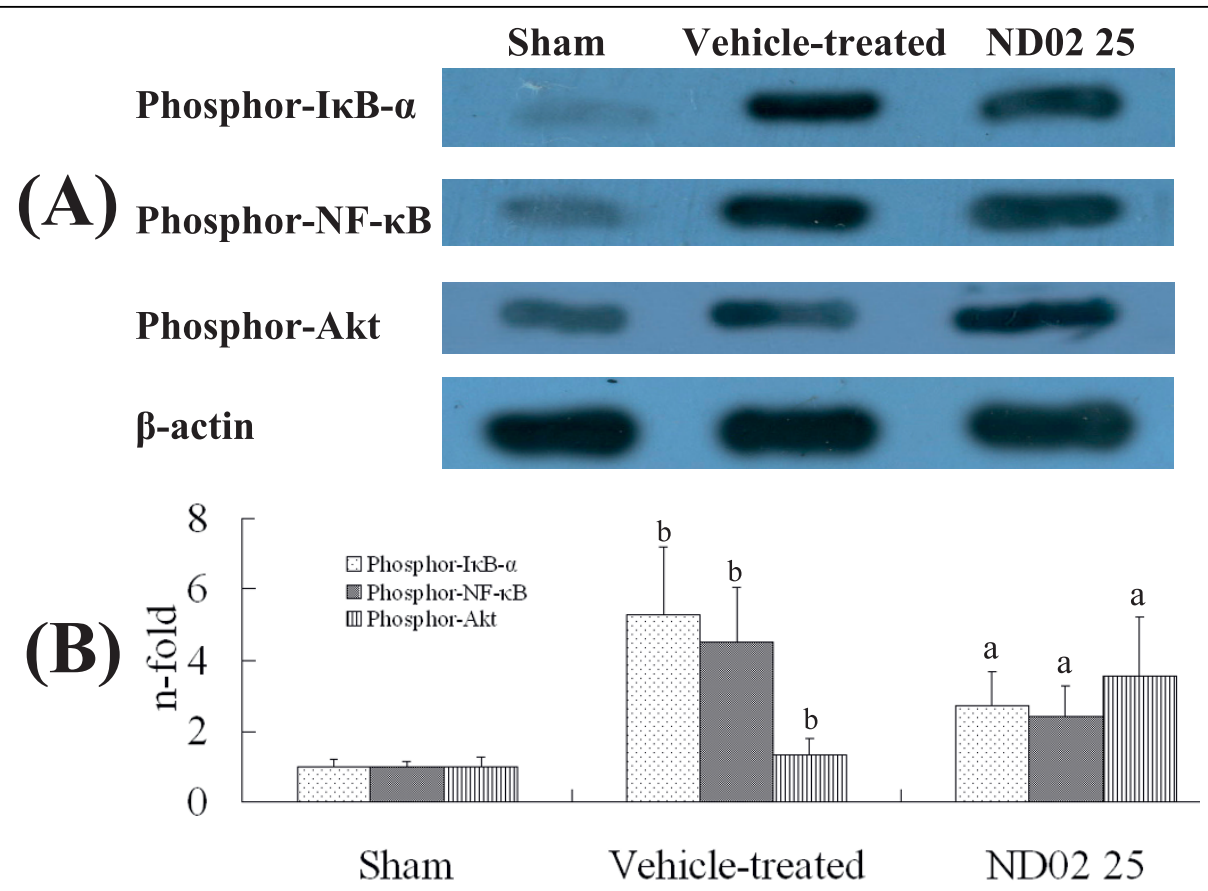

Figure 4 Effects of ND02 on phosphor-NF- $\kappa$ B, phosphor- $1 \kappa \mathrm{B}-\alpha$ and phosphor-Akt in cerebral I/R rats by western blots analysis $24 \mathrm{~h}$ after I/R. Rats were subjected to middle cerebral artery occlusion (MCAO) and reperfusion (I/R) for $23 \mathrm{~h}$. Total protein extracts were prepared and assayed for phosphor-NF- $\kappa$ B, phosphor- $\mid \kappa \mathrm{B}-\alpha$ and phosphor-Akt by western blot analysis, and blots were normalized to $\beta$-actin expression. Results are expressed as fold increase over sham group, $\mathrm{n}=5$. ${ }^{\mathrm{a}} P<0.01$ vs. vehicle-treated group. ${ }^{\mathrm{b}} p<0.01$ vs. sham group. Significance was determined by one-way analysis of ANOVA followed by Dunnett's test.

deficient in NF- $\kappa \mathrm{B}$ are less susceptible to cerebral I/R [49]. Akt phosphorylates $\mathrm{I} \kappa \mathrm{B}$ kinase, and activated $\mathrm{I} \kappa \mathrm{B}$ $\alpha$, in turn, causes activation and nuclear translocation of NF- $\kappa \mathrm{B}$-dependent prosurvival genes [50]. A curb on the $\mathrm{NF}-\kappa \mathrm{B}$ signaling pathway by ND02 is implicated in its molecular regulation of I/R-triggered inflammatory reactions, because western blot analysis (Figure 4) verified that phosphorylated $\mathrm{I} \kappa \mathrm{B}-\alpha$ and $\mathrm{NF}-\kappa \mathrm{B}$ are alleviated, but phosphorylated Akt is increased. Therefore, we believe that the protective effects of ND02 could be due, in large part, to suppression of inflammatory cascades through an Akt-dependent NF- $\kappa$ B signaling pathway.

In summary, the results of the current study suggest that ND02 exhibits significant neuroprotective effects during cerebral I/R injury, including attenuation of BBB breakdown, decreased infarct volume, alleviated cerebral damage, and reduced phosphorylated $\mathrm{I} \kappa \mathrm{B}-\alpha$ and NF- $\kappa \mathrm{B}$ proteins in ischemic brain tissue. These effects of ND02 correlate with inhibition of the inflammatory response. Moreover, unpublished results from our pharmacokinetic laboratory suggest that ND02 might penetrate the blood-brain barrier. These findings point to a therapeutic potential for ND02 as a useful anti-inflammatory lead compound in early cerebral I/R injury.

\section{Abbreviations}

ND02: 6-O-acetyl shanzhiside methyl ester; MCAO: middle cerebral artery occlusion; NF- $\kappa \mathrm{B}$ : nuclear transcription factors kappaB; I/R: ischemia and reperfusion; BBB: blood-brain barrier.

\section{Acknowledgements}

We thank the colleagues of chemistry laboratory for his generous assistance in 6-O-acetyl shanzhiside methyl ester extraction and isolation.

\section{Author details}

${ }^{1}$ Institute of Material Medica, Binzhou Medical University, Yantai, 264003, PR China. ${ }^{2}$ State Key Laboratory of Long-acting and Targeting Drug Delivery Technologies (Luye Pharma Group Ltd.), Yantai, 264003, PR China. ${ }^{3}$ School of Pharmacy, Yantai University, Yantai 264003, PR China.

\section{Authors' contributions}

WJ, S Z and F F contributed to the design of the study. $\mathrm{H} \mathrm{Z}$ contributed to NeuN staining. $\mathrm{W} \mathrm{J}, \mathrm{JH}$ and $\mathrm{HZ}$ contributed to operation of animal experiment. All authors read the manuscript, studied it critically for its intellectual content and approved the final draft.

\section{Competing interests}

The authors declare that they have no competing interests.

Received: 2 June 2010 Accepted: 14 September 2010

Published: 14 September 2010

\section{References}

1. Fisher M, STAIR: Recommendations for advancing development of acute stroke therapies: stroke therapy academic industry roundtable. Stroke 2003, 34:1539-1546. 
2. Samson $Y$, Lapergue $B$, Hosseini $H$ : Inflammation and ischemic stroke: current status and future perspectives. Revue Neurol 2005, 161:1177-1182.

3. Chamorro A, Hallenbeck J: The harms and benefits of inflammatory and immune responses in vascular disease. Stroke 2006, 3:291-293.

4. Tripathy D, Grammas P: Acetaminophen inhibits neuronal inflammation and protects neurons from oxidative stress. J Neuroinflamm 2009, 6:10.

5. Clemens JA, Stephenson DT, Smalstig EB, Dixon EP, Little SP: Globa ischemia activates nuclear factor- $\kappa \mathrm{B}$ in forebrain neurons of rats. Stroke 1997, 28:1073-1081.

6. Huang CY, Fujimura M, Noshita N, Chang YY, Chan PH: SOD1 downregulates NF-kappaB and c-Myc expression in mice after transient focal cerebral ischemia. J Cereb Blood Flow Metab 2001, 21:163-173.

7. Stephenson D, Yin T, Smalstig EB, Hsu MA, Panetta J, Little S, Clemens J: Transcription factor nuclear factor-kappa $B$ is activated in neurons after focal cerebral ischemia. J Cereb Blood Flow Metab 2000, 20:592-603.

8. Gabriel C, Justicia C, Camins A, Planas AM: Activation of nuclear factorkappaB in the rat brain after transient focal ischemia. Brain Res Mol Brain Res 1999, 65:61-69.

9. Grilli M, Pizzi M, Memo M, Spano P: Neuroprotection by aspirin and sodium salicylate through blockade of NF- $\kappa$ B activation. Science 1996, 274:1383-1385.

10. Wang YH, Wang WY, Chang CC, Liou KT, Sung YJ, Liao JF, Chen CF Chang S, Hou YC, Chou YC, Shen YC: Taxifolin ameliorates cerebral ischemia-reperfusion injury in rats through its anti-oxidative effect and modulation of NF-kappa B activation. J Biomed Sci 2005, 13:127-141.

11. Khan M, Elango C, Ansari MA, Singh I, Singh AK: Caffeic acid phenethyl ester reduces neurovascular inflammation and protects rat brain following transient focal cerebral ischemia. J Neurochem 2007, 102:365-377.

12. Wen $Y$, Yang S, Liu R, Perez E, Yi KD, Koulen P, Simpkins JW: Estrogen attenuates nuclear factor-kappa $B$ activation induced by transient cerebral ischemia. Brain Res 2004, 1008:147-154.

13. Pereira MP, Hurtado O, Cardenas A, Bosca L, Castillo J, Davalos A, Vivancos J, Serena J, Lorenzo P, Lizasoain I, Moro MA: Rosiglitazone and 15-deoxy-Delta12,14-prostaglandin J2 cause potent neuroprotection after experimental stroke through noncompletely overlapping mechanisms. J Cereb Blood Flow Metab 2006, 26:218-229.

14. Noshita N, Lewen A, Sugawara T, Chan PH: Evidence of phosphorylation of Akt and neuronal survival after transient focal cerebral ischemia in mice. J Cereb Blood Flow Metab 2001, 21:1442-1450.

15. Yano S, Morioka M, Fukunaga K, Kawano T, Hara T, Kai Y, Hamada J, Miyamoto $E$, Ushio $Y$ : Activation of Akt/protein kinase B contributes to induction of ischemic tolerance in the CA1 subfield of gerbil hippocampus. J Cereb Blood Flow Metab 2001, 21:351-360.

16. Zhao H, Shimohata T, Wang JQ, Sun G, Schaal DW, Sapolsky RM, Steinberg GK: Akt contributes to neuroprotection by hypothermia against cerebral ischemia in rats. J Neurosci 2005, 25:9794-9806.

17. Kitano H, Young JM, Cheng J, Wang L, Hurn PD, Murphy SJ: Genderspecific response to isoflurane preconditioning in focal cerebral ischemia. J Cereb Blood Flow Metab 2007, 27:1377-1386.

18. Song YS, Narasimhan P, Kim SG, Jung JE, Park EH, Chan PH: The role of Akt signaling in oxidative stress mediates NF- $\kappa \mathrm{B}$ activation in mild transient focal cerebral ischemia. J Cereb Blood Flow Metab 2008, 28:1917-1926.

19. Dhandapani KM, Wade FM, Wakade C, Mahesh VB, Brann DW: Neuroprotection by stem cell factor in rat cortical neurons involves AKT and NFkappaB. J Neurochem 2005, 95:9-19.

20. Zhu Y, Culmsee C, Klumpp S, Krieglstein J: Neuroprotection by transforming growth factor-beta1 involves activation of nuclear factorkappaB through phosphatidylinositol-3-OH kinase/Akt and mitogenactivated protein kinase-extracellular-signal regulated kinase1,2 signaling pathways. Neuroscience 2004, 123:897-906.

21. Ozes ON, Mayo LD, Gustin JA, Pfeffer SR, Pfeffer LM, Donner DB: NF- $\kappa$ B activation by tumour necrosis factor requires the Akt serine-threonine kinase. Nature 1999, 401:82-85.

22. Yi JH, Huang XP, Chen Y, Luo ZY, Zhong CC: Studies on the iridoid glucosides of the root of Lamiophlomis rotata (Benth.) Kudo, a medicinal plant in Tibet. Acta Pharmaceutica Sinica 1997, 32:360-362.

23. Jiang WL, Fu FH, Zheng SG, Zhang DL, Zhu HB, Hou J: 8-O-acetyl shanzhiside methylester attenuates apoptosis and ameliorates mitochondrial energy metabolism in rat cortical neurons exposed to oxygen-glucose deprivation. Eur J Pharmacol 2010, 629:20-24.
24. Yu ZX, Wang GL, Bianba C, Lin RC: Studies on chemical constituents in root of Phlomis medicinalis I [Article in Chinese]. Zhongguo Zhong Yao Za Zhi 2006, 31:656-658.

25. Jiang WL, Zhang SP, Zhu HB, Hou J, Tian JW: Cornin ameliorates cerebral infarction in rats by antioxidant action and stabilization of mitochondrial function. Phytother Res 2010, 24:547-552.

26. Minematsu K, Li L, Sotak CH, Davis MA, Fisher M: Reversible focal ischemic injury demonstrated by diffusion-weighted magnetic resonance imaging in rats. Stroke 1992, 23:1304-1310.

27. Vink R, Young A, Bennett CJ, Hu X, Connor CO, Cernak I, Nimmo AJ: Neuropeptide release influences brain edema formation after diffuse traumatic brain injury. Acta Neurochir Supp/ 2003, 86:257-260.

28. Vakili A, Hosseinzadeh F, Sadogh $T$ : Effect of aminoguanidine on postischemic brain edema in transient model of focal cerebral ischemia. Brain Res 2007, 1170:97-102.

29. Swanson RA, Morton MT, Tsao-Wu G, Savalos RA, Davidson C, Sharp FR: A semiautomated method for measuring brain infarct volume. J Cereb Blood Flow Metab 1990, 10:290-293.

30. Son HY, Han HS, Jung HW, Park YK: Panax notoginseng attenuates the infarct volume in rat ischemic brain and the inflammatory response of microglia. J Pharmacol Sci 2009, 109:368-379.

31. Graham SH, Chen J: Programmed cell death in cerebral ischemia. J Cereb Blood Flow Metab 2001, 21:99-109.

32. Dirnagl U, ladecola C, Moskowitz MA: Pathobiology of ischaemic stroke: an integrated view. Trends Neurosci 1999, 22:391-397.

33. Durukan A, Tatlisumak T: Acute ischemic stroke: overview of major experimental rodent models, pathophysiology, and therapy of focal cerebral ischemia. Pharmacol Biochem Behav 2007, 87:179-197.

34. Mullen RJ, Buck CR, Smith AM: NeuN, a neuronal specific nuclear protein in vertebrates. Development 1992, 116:201-211.

35. Wolf HK, Buslei R, Schmidt-Kastner R, Schmidt-Kastner PK, Pietsch T, Wiestler OD, Blumcke I: NeuN: a useful neuronal marker for diagnostic histopathology. J Histochem Cytochem 1996, 44:1167-1171.

36. Davoli MA, Fourtounis J, Tam J, Xanthoudakis S, Nicholson D, Robertson GS, $\mathrm{NgG} Y, X u$ D: Immunohistochemical and biochemical assessment of caspase- 3 activation and DNA fragmentation following transient focal ischemia in the rat. Neuroscience 2002, 115:125-136.

37. Sugawara T, Lewen A, Noshita N, Gasche Y, Chan PH: Effects of global ischemia duration on neuronal, astroglial, oligodendroglial, and microglial reactions in the vulnerable hippocampal CA1 subregion in rats. J Neurotrauma 2002, 19:85-98.

38. Bendel O, Alkass K, Bueters T, von Euler M, von Euler G: Reproducible loss of CA1 neurons following carotid artery occlusion combined with halothane-induced hypotension. Brain Res 2005, 1033:135-142.

39. Ajmo CT Jr, Vernon DO, Collier L, Pennypacker KR, Cuevas J: Sigma receptor activation reduces infarct size at $24 \mathrm{~h}$ after permanent middle cerebral artery occlusion in rats. Curr Neurovasc Res 2006, 3:89-98.

40. Liu F, Schafer DP, McCullough LD: TTC, Fluoro-Jade B and NeuN staining confirm evolving phases of infarction induced by middle cerebral artery occlusion. J Neurosci Methods 2009, 179:1-8.

41. Ding ZL, Marchand VC, Croci N, Plotkine M, Margaill I: L-NAME reduces infarction, neurological deficit and blood-brain barrier disruption following cerebral ischemia in mice. Eur J Pharmacol 2002, 457:137-146.

42. Kondo T, Reaume AG, Huang TT, Carlson E, Murakami K, Chen SF, Hoffman EK, Scott RW, Epstein CJ, Chan PH: Reduction of CuZn-superoxide dismutase activity exacerbates neuronal cell injury and edema formation after transient focal cerebral ischemia. J Neurosci 1997, 17:4180-4189.

43. Yang GY, Gong C, Qin Z, Liu XH, Lorris Betz A: Tumor necrosis factor alpha expression produces increased blood-brain barrier permeability following temporary focal cerebral ischemia in mice. Brain Res Mol Brain Res 1999, 69:135-143.

44. Ayata C, Ropper A: Ischaemic brain edema. J Clin Neurosci 2002, 9:113-124.

45. Hoda MN, Singh I, Singh AK, Khan M: Reduction of lipoxidative load by secretory phospholipase $\mathrm{A} 2$ inhibition protects against neurovascular injury following experimental stroke in rat. J Neuroinflammation 2009, $6: 21$.

46. Fisher M, Feuerstein G, Howells DW, Hurn PD, Kent TA, Savitz SI, Lo EH, STAIR Group: Update of the stroke therapy academic industry roundtable preclinical recommendations. Stroke 2009, 40:2244-2250. 
47. Pahl HL: Activators and target genes of Rel/NF-kappaB transcription factors. Oncogene 1999, 18:6853-6866.

48. Waddick KG, Uckun FM: Innovative treatment programs against cancer: II. Nuclear factor-kappaB as a molecular target. Biochem Pharmacol 1999, 57:9-17.

49. Schneider A, Martin-Villalba A, Weih F, Vogel J, Wirth T, Schwaninger M: NFkappaB is activated and promotes cell death in focal cerebral ischemia. Natural Med 1999, 5:554-559.

50. Kane LP, Shapiro VS, Stokoe D, Weiss A: Induction of NF- $\kappa$ B by the Akt/ PKB kinase. Curr Biol 1999, 9:601-604.

doi:10.1186/1742-2094-7-55

Cite this article as: Jiang et al: Inhibition of nuclear factor- $\kappa$ B by 6-Oacetyl shanzhiside methyl ester protects brain against injury in a rat model of ischemia and reperfusion. Journal of Neuroinflammation 2010 7:55

\section{Submit your next manuscript to BioMed Central} and take full advantage of:

- Convenient online submission

- Thorough peer review

- No space constraints or color figure charges

- Immediate publication on acceptance

- Inclusion in PubMed, CAS, Scopus and Google Scholar

- Research which is freely available for redistribution

Submit your manuscript at www.biomedcentral.com/submit 